\title{
The Distinctiveness of Small Business Owners Openness, and Conscientiousness With the Influence on Financial Institution Risk Management With the Logistic Regression Analysis in the United States
}

\author{
Luis Moncayo \\ University of Maryland Global Campus \\ Karina Kasztelnik \\ Tennessee State University
}

\begin{abstract}
No known empirical research has focused on exploring relationship between owners' openness, and conscientiousness with the influence on financial institution risk management in the United States. These studies cover the roots of microfinance, observed trends in the microfinance industry, the factors that have caused these trends, and the financial implications that these monies have had on the recipients and the economies in which they exist. The principal objective of this research study was to investigate the distinctiveness of small business and all other behavioral microfinance. Not significant association for the distinctiveness of small business owners' openness, and conscientiousness were identified for our variables in this research study. Our findings of this study imply an overall significant effect of openness, and conscientiousness on small business owners' ability to secure microloans and the influence on macroeconomy along with bank risk management after controlling for age, gender, and ethnicity. The article can contribute to a better understanding of microfinance customer behaviors and the general influence on financial institution risk.
\end{abstract}

Keywords: financial institution, business risk, business behaviors, microfinance

\section{BACKGROUND OF THE STUDY}

The microfinance plays a key role in the world economics and in the risk management for the best datadriven decision. Various scholars have researched various matters relating to microfinance. These studies cover the roots of microfinance, observed trends in the microfinance industry, the factors that have caused these trends, and the financial implications that these monies have had on the recipients and the economies in which they exist. The scholarly works have also depicted the real-life situations as case studies and examples to illustrate the effects of microfinance while using figures to illustrate the implications and trends.

DeYoung (2015) provided retrospective evaluation about recent research studies conducted in the United States to determine who bears the most risk when funding small businesses. Risks associated with lending to small businesses are usually spread over three sectors (entrepreneurs, bank lenders, and tax payers), and the level of risk bearing varies depending on the current business cycle. Overall, the level of 
risk is lower when bank-borrower relationships are stronger. Khrishnan, Nandy, and Puri (2014) conducted a research study that provided evidence that greater access to financing can significantly allow financially constrained businesses to invest in projects that otherwise would not be able to attain. Fracassi, Garmaise, Kogan, and Navidad (2016) conducted a regression research study using data on startup loan applicants from a lender; the results suggested that startups receiving funding are dramatically more likely to survive, enjoy higher revenues, and create more jobs than their counterparts that did not.

Banerjee, Dufflo, Glennerster, and Kinnan (2015) conducted a research study that provided evidence of the effect of microfinance by conducting the financial situations of the data sample before and after they had access to micro financial resources. This analysis provides the background of the financial situations before the onset of microfinance. Similarly, Beck, Degryse, De Haas, and Van Horen (2017) provided empirical evidence to show that relationship lending alleviates credit constraints during cyclical downturn. The positive effect of relationship lending in an economic downturn is strongest for smaller firms in regions where downturn is more severe. Researchers have studied personality factors in the field of management; however, not from actions surrounding finance (Barrick \& Mount, 1991).

\section{PROBLEM STATEMENT}

It is not known if and to how the personality traits of small business owners are related to their ability to secure microloans for their business needs. Microfinance loans have been on the rise since the 1970s. Microfinance has become an important developmental tool for assisting small businesses in times of need. The general problem is that it is not known why some small business owners are able to secure small loans to finance their small businesses while others do not.

\section{PURPOSE OF THE STUDY}

The independent variables of personality traits are the participants' levels of extraversion, agreeableness, openness, conscientiousness, and neuroticism, as measured by the Big Five Inventory (John \& Srivastava, 1999). The definition of the dependent variable is whether the participant was able to secure microloans for their business needs. The study will control for demographic indicators of age, gender, and ethnicity. The sample will be small business owners who live in the United States. I will use Survey Monkey Audience to solicit participants who meet these criteria.

The theoretical perspectives analyzed herein illustrate that personal attribute of small business owners have a bearing on their ability to secure funding from financial institutions (Dlugosch et al., 2018). The insight from the analysis herein shows that there is a need for a positive social change among investors and small business owners to enable their attainment of microloans from financial institutions. The purpose of this quantitative, non-experimental, correlational study is to explore how the personality traits of small business owners related to their ability to secure microloans for their business needs. The scope of the study includes small business owners in rural locations of the United States. I will collect data using a surveybased non-experimental design and analyze the data using a binary logistic regression.

\section{RESEARCH QUESTIONS \& HYPOTHESES}

RQ1: Is there a relationship between the personality traits, and openness of small business owners and the ability to secure microloans for their business needs?

$\boldsymbol{H}_{0}$. The personality traits do not significantly correlate to openness of small business owners and the ability to secure microloans for their business needs, controlling for age, gender and ethnicity of the individual seeking the loan. 
$\boldsymbol{H}_{1}$. The personality traits do significantly correlate to openness of small business owners and the ability to secure microloans for their business needs, controlling for age, gender and ethnicity of the individual seeking the loan.

RQ2: Is there a relationship between the personality traits, and conscientiousness of small business owners and the ability to secure microloans for their business needs?

$\boldsymbol{H}_{0 .}$ The personality traits do not significantly correlate to conscientiousness of small business owners and the ability to secure microloans for their business needs, controlling for age, gender and ethnicity of the individual seeking the loan.

$\boldsymbol{H}_{1}$. The personality traits do significantly correlate to conscientiousness of small business owners and the ability to secure microloans for their business needs, controlling for age, gender and ethnicity of the individual seeking the loan.

I defined the independent variables of personality traits as the participants' levels of openness, conscientiousness as measured by the Big Five Inventory (John \& Srivastava, 1999). The dependent variable is whether the participant was able to secure microloans for their business needs. I will control for the demographic indicators of age, gender, and ethnicity. The personality traits stem from the Big Five traits. Openness to experience is an attribute that characterizes an individual who is open to novel experiences and ideas (Allen \& DeYoung, 2017). Conscientiousness is the characteristic of individuals who are dependable and demonstrate perseverance and handwork. Individuals who are associated with this attribute are overly anxious, worried, embarrassed, and emotional (John \& Srivastava, 1999).

\section{THEORETICAL FOUNDATION}

The Big Five Factor Theory aligns with the notion that small business owners' personality traits may directly affect their ability to secure financing for their business. Personal traits of small business owners are important in the determination of their suitability to receive credit from lenders and financial institutions. Generally, economists have emphasized the specific attributes of entrepreneurs in the determination of their ability to secure loans and their potential to repay the loans (McGuiness \& Hogan, 2016). Furthermore, lenders have focused on the relationship between the personal attributes of entrepreneurs and their personal finances. The Big Five model is imperative in the determination of the economic outcomes of entities (Kasztelnik, 2020).

Essentially, the Big Five personality traits enable lenders to assess the suitability of entrepreneurs to get loans from micro finances. Therefore, the Big Five-factor theory collaborates with the proposition that the personality traits of small business owners have a bearing on their ability to secure finances for their enterprises.

\section{NATURE OF THE STUDY}

Because of the lack of randomly assigned groups and the inability to manipulate variables, this design is appropriate for the present study. Researchers use correlational design when relational inferences, rather than causal inferences, are made (Field, 2013). I will use this methodology and design to collect and analyze objective data using the Big Five Inventory (John \& Srivastava, 1999) and a demographic questionnaire to answer the research question. The collected data will represent the demographic indicators, as well as the independent variables of personality traits and the dependent variable of ability to secure microloans. A binary logistic regression will generate the answers to the research questions. 


\section{DEFINITIONS}

\section{Conscientiousness}

Conscientiousness is the characteristic of individuals who are dependable and demonstrate perseverance and handwork. Individuals who are associated with this attribute are overly anxious, worried, embarrassed, and emotional. Emotionally stable people are more likely to be robust entrepreneurs due to their high tolerance for stress. I will measure the continuous independent variables with the Big Five Inventory (John \& Srivastava, 1999).(John \& Srivastava, 1999).

\section{Openness to Experience}

Openness to experience is an attribute that characterizes an individual who is open to novel experiences and ideas. Individuals who are open to experiences are imaginative, reflective and innovative (Allen \& DeYoung, 2017). As a continuous independent variable, I will measure openness to experience with the Big Five Inventory (John \& Srivastava, 1999).

\section{LITERATURE REVIEW}

Small businesses often struggle to secure financing for their financial needs (Krishman, Nandy, \& Puri, 2014). While some concrete elements, like credit score and personal finance history, influence funding (McGuiness \& Hogan, 2016), it is not known whether and how personal characteristics influence why some small business owners are able to secure small loans to finance their small businesses while others do not. The proposed study will address the gap in the literature by extending the work of Baluku, Kikooma, and Kibanja (2016) and Hachana, Berraies, and Ftiti (2018), who recommended that future researchers explore how personality traits can explain the success and failure of entrepreneurial ventures as well as examine the moderating effect of conscientiousness and neuroticism on the relationship between startup capital and entrepreneurial success.

Each set trait has subdivisions collected based on the relationship of facets appearing as a sub-level hierarchical aspect of a person's characteristic traits and are measured by the Big Five Aspect Scale. Figure 1 examples the sub-traits measured under such and are valuable in determining success or failure of small business ventures.

\section{FIGURE 1}

\section{FROM BIG FIVE SCALE - CONSCIENTIOUSNESS AND OPENNESS/INTELLECT}

\begin{tabular}{|c|c|}
\hline Conscientiousness & Openness/Intellect \\
\hline Industriousness & Openness \\
\hline Orderliness & Intellect \\
\hline
\end{tabular}

Source: Compiled by Authors

Contemporarily, many researchers have assessed change in the Big Five personality traits in different contexts. Farrington (2012) conducted a study to investigate whether a relationship exists between possessing certain personality traits and small business success. The five-factor model of personality, extraversion, conscientiousness, openness to experience, agreeableness and neuroticism were the focus. The findings show that individuals with high levels of personality traits such as: extraversion, censoriousness and open to experience are more likely to have successful small businesses. Moreover, Azucar, Marengo, and Settanni (2018) evaluated how the Big Five traits related to people's consumption 
habits, preferences, and motivations. Azucar et al. examined each trait as a specific means for targeting audiences, finding people were attracted to items in ads that associated with their own personality traits. In business, it is common practice to use factor analysis with the basic five personality traits to derive those positive traits that will help make a business successful.

\section{CONSCIENTIOUSNESS}

Under the Big Five, conscientiousness refers to dependability, carefulness, thoroughness, organization and responsibility (Farrington, 2012). Individuals who are conscientious are hardworking and selfdisciplined, with a strong need to reduce uncertainty (Farrington, 2012). Additionally, conscientious individuals have leadership skills, and thus are very capable of managing businesses (Mabunda et al., 2016).

Conscientiousness can significantly influence personal behaviors and success. Ali (2019) collected survey data from 613 currently enrolled college students regarding innovative thinking and satisfaction with life perceptions. The answers were measured using a five-point Likert scale with one for very dissatisfied and 5 for very satisfied. Findings showed that conscientiousness was a positive trait in terms of success, innovative thinking, and satisfaction with life perceptions (Ali, 2019). Conscientiousness may relate to increased psychological capital, which can increase entrepreneurs' levels of effort towards achieving business goals (Mabunda et al., 2016).

Ranwala and Dissanayake (2016), attempted to identify the impact of the Big Five Personality Traits on entrepreneurial inclination, the results of their study showed that entrepreneurial inclination related positively to openness to experience, extroversion, neuroticism, agreeableness, and conscientiousness for those participants with a significantly higher propensity for these specific personality traits. Based on previous research regarding the connection between Extraversion and small business owners' ability to secure microloans, I developed the following hypothesis:

$\boldsymbol{H}_{0 .}$ The personality traits do not significantly correlate to conscientiousness of small business owners and the ability to secure microloans for their business needs, controlling for age, gender and ethnicity of the individual seeking the loan.

$\boldsymbol{H}_{1}$. The personality traits do significantly correlate to conscientiousness of small business owners and the ability to secure microloans for their business needs, controlling for age, gender and ethnicity of the individual seeking the loan.

\section{OPENNESS TO EXPERIENCE}

Openness to experience is associated with originality, open-mindedness, artistry, insightfulness, imaginativeness, and intelligence (Farrington, 2012). This trait determines whether a person is likely to seek out new ideas and think creatively; however, it can also influence practical-mindedness and efficiency. Individuals who are open minded tend to have strong need for change; therefore, leaders who are open to new experiences often seek out taking risks which can be positive for the business (Farrington, 2012). This trait can help entrepreneurs understand customer needs and learn how to deal with competition and market trends. Individuals that have openness to experience tend to question the current ways of doing businessthis questioning, in addition to higher intellectual capacity, often allows individuals who are open to experience identify new opportunities (Mabunda et al., 2016).

Hachana et al. (2018) compared men and women to determine what relationship each of the five personality traits correlated with success. The findings showed that the most significant personality factors associated with business success were openness to experience and conscientiousness; men and women were equal in these traits. Agreeableness, which was more associated with women, related less closely to success. While neuroticism did not relate to success in business, the trait was higher in women than in men. Extroversion, higher in men, had no effects on entrepreneurial success. The authors concluded that entrepreneurial success related to openness to experience, conscientiousness, and agreeableness. Based on 
previous research regarding the connection between Openness to experience and small business owners' ability to secure microloans, I developed the following hypothesis:

$\boldsymbol{H}_{0 .}$ The personality traits do not significantly correlate to openness of small business owners and the ability to secure microloans for their business needs, controlling for age, gender and ethnicity of the individual seeking the loan.

$\boldsymbol{H}_{1}$. The personality traits do significantly correlate to openness of small business owners and the ability to secure microloans for their business needs, controlling for age, gender and ethnicity of the individual seeking the loan.

\section{BIG FIVE PERSONALITY TRAITS AND MOTIVATION IN BUSINESS}

Researchers have assessed the relationship between personality traits and success in the business enterprise (Farrington, 2012; Obschonka \& Stuetzer, 2017). The overriding question of whether Big Five personality traits affect success has been observed by multiple researchers (Ali, 2019; De Bortoli, da Costa Jr., Goulart, \& Campara, 2019; Gambetti \& Giusberti, 2017; Hassan, Akhtar, \& Yilmaz, 2016; Kerr, Kerr, \& Xu, 2018; Palazzeschi, Bucci, \& Di Fabio, 2018; Pang et al., 2016). Specifically, correlative studies from multiple experts in different industries and disciplines have observed factors that prompt motivation based on a person's characteristics (Anwar, Xiao, Fiaz, Ikram, \& Younas, 2017; Chatterje \& Das, 2015; Murugesan \& Jayavelu, 2017; Ranwala \& Dissanayake, 2016). Researchers have examined key personality traits associated with motivation and performance, and therefore, with business success.

Conscientiousness is one of the key personality traits that related to success and motivation. Hassan, Akhtar, and Yilmaz (2016) measured the work performance of 612 microfinance employees to determine whether conscientiousness associated with success. The authors used a descriptive, hypotheses testing research design and interviewed the participants in one-on-one settings. Findings stemmed from collected data sub-categorized five dimensions of conscientiousness, including orderliness, self-discipline, dutifulness, self-efficacy, and striving for achievement. Kerr, Kerr, and Xu (2018) examined baseline models using personality traits from the Big Five models as well as from self-efficacy, need for achievement, innovativeness, and locus of control to determine positive outcomes in entrepreneurial behavior (Delanoy \& Kasztelnik, 2020). The author's comprehensive literature examination produced 23 studies used in a meta-analysis to determine patterns of probability for personality traits associated with successful entrepreneurship versus managers (Kerr et al., 2018). According to Kerr et al., (2018) conscientiousness was most common with entrepreneurs but not with managers.

The relation between Big Five personality traits and business success is not uncontested. Findings indicated that personality traits affect success in entrepreneurial intent and perception, yet some experts claim personality only affects the motivation to succeed, not the success itself (Oyeku et al., 2014; Staniewski, Janowski, \& Awruk, 2016; Viinikainen et al., 2017). Moreover, while some experts find the Big Five personality trait more comprehensive when explaining how entrepreneurs are successful, others assert that personality traits beyond just the Big Five have merit (Leutner, Ahmetoglu, Akhtar, \& Chamorrow-Premuzic, 2014). For example, personality traits considered part of the Big Five, such as extroversion, openness to experience, conscientiousness, and agreeableness, are considered relevant to entrepreneurial success, yet other traits are also associated, such as responsibility, aggression, and motivation (Viinikainen et al., 2017).

\section{IMPORTANCE OF MICROLOANS FOR SMALL BUSINESS OWNERS}

Microloans, or microfinance, encompass similar features of other loan options, except those receiving such loans are typically small business owners unable to secure a primary source of borrowing or finance (Brau \& Woller, 2004). However, small business owners are often not treated the same regarding microloan availabilities. Microfinance is a key part of the finance world, yet the core elements of microfinance highly 
differ from the definition of finance itself. Microfinance is not part of mainstream financial arenas, nor is it often found in entrepreneurship finance literature (Brau \& Woller, 2004). Microfinance or micro loan is provisional for those businesspersons who are low-income or even unemployed and have no other means for financial lending services.

Microfinance may significantly influence the success of SMEs. Obebo et al. (2018) used a crosssectional survey to determine if small enterprises failed due to the financial exclusion or limited loan capabilities due to shortages in operating funds. The authors examined data collected from the 2016 FinAccess Dataset and observed the abilities and risks from owners of small enterprises. The data indicated positive effects on the performance of the owners who were able to garner microfinance funding. Banerjee, Dufflo, Glennerster, and Kinnan (2015) conducted a research study that provided evidence of the impact of microfinance by conducting the financial situations of the data sample before and after they had access to micro financial resources. The authors found that this impact was substantial as the success stemmed from receiving the microloan and only when the owners were able to recognize their financial situations were dire (Dufflo et al., 2015). Conversely, Kariv and Coleman (2015) observed the impact small business microloans had on new company performance. The authors used longitudinal data from the Panel Study of Entrepreneurial Dynamics and examined whether the benefit of a microloan overrode the benefit of a bank loan (Umadia \& Kasztelnik, 2020). No significant findings suggested that micro- or bank loan prompted any given successful endeavor. Business performance was not determined by where the money came from, but from how the entrepreneur obtained and put it to use (Kariv \& Coleman, 2015).

\section{ENVIRONMENTAL FACTORS}

Taylor (2017) examined a sample population $(\mathrm{N}=27)$ of U.S. based small business owners to determine reasons for receiving or being turned down for microloans offered by the Federal Reserve Bank of New York. The author used a survey instrument with questions relating to the participants' borrowing habits and analyzed the collected data finding eight common themes for participants unable to receive funding. The themes found included the uncertainty of the current economic climate, lack of collateral, gender or ethnic bias, bad credit history, high operating expense with the slow promise of growth, lack of cash flow, the type of business, and owner's unclear understanding of the financing processes influenced funding. Suggested reasons beyond personality traits were results for Taylor's (2017) examination and led the author to conclude environmental elements were more likely than a personality to result in a person not receiving microloan. Similarly, Marquita, Albion, Diemer, and Morphia (2016) aimed to determine what factors impacted policy intervention related to small business lending and if such factors were evident in the association of entrepreneurs, was banking behavior consistent in providing loan allowances to all borrowers. The authors showed that microloans given to subprime borrowers influenced acceptance or denial of loans based on the perceptions of the involved loan officer (Marquita et al., 2016).

\section{ASSUMPTIONS}

The rationale for carrying out the study is to evaluate the implications of personal traits on the ability of small business owners in the rural United States to obtain capital for their business. I assumed that those small business owners who are located in the rural regions of the United States would be more interested to use the provided information in their businesses. I assumed that small business owners in the rural United States would have a desire to use the information provided to understand the impact of personality traits and funding. I also assumed that the participants of the study responded to the survey questions in an honest manner. I will inform participants that their participation is strictly voluntary and that their individual responses will not link back to them, so issues of response bias that may influence their responses will be limited. 


\section{SIGNIFICANCE TO SOCIAL CHANGE}

This study will contribute highly to the improvement of social economic conditions of small business owners in rural settings. The study will be imperative in affecting positive social change, which will lead to improved quality of life. This will enable the small business owners to see the importance of behavioral change, which will add more value to their business as well as improve their economic positions.

\section{RESEARCH DESIGN}

The researcher will use a quantitative, non-experimental, correlational study. A researcher uses quantitative methodology to determine the existence of relationships or causality between two or more variables using numerical data (Johnson \& Christensen, 2019). A quantitative approach is appropriate for this study because the purpose of this study is to examine relationships between variables that are numerically measurable. The independent variables in this study include the personality traits of openness, conscientiousness as measured by the Big Five Inventory (John \& Srivastava, 1999). The dependent variable is the ability to secure a microloan. The covariates in this study will be age, gender, and ethnicity. The independent, dependent, and covariate variables are numerically measurable. Therefore, a quantitative methodology is aligned with the purpose and research questions of this study.

More specifically, the researcher will use a correlational research design for this study. A correlational design is used when the researcher needs to explore the direction or the strength of the relationship between the independent and dependent variables. Based on the purpose of the study, the independent variables include personality traits, (specifically, the participants' levels of extraversion, agreeableness, openness, conscientiousness, and neuroticism, as measured by the Big Five Inventory). The dependent variable is whether the participant was able to secure microloans for their business needs. The study will control for demographic indicators of age, gender, and ethnicity. These variables are aligned with the purpose and research questions of the study. Through a correlational design, the researcher can determine either a positive or negative relationship between variables. Therefore, a correlational research design is appropriate for this study.

FIGURE 2

\section{G*POWER SAMPLE CALCULATION}

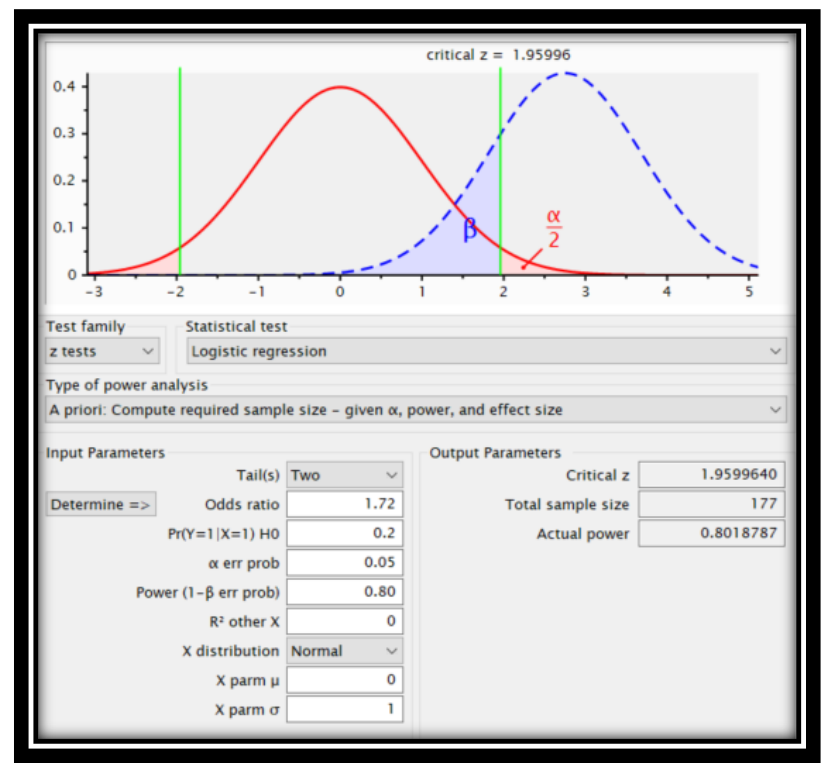

Source: Compiled by Authors in G-Power. 


\section{POPULATION}

The general population of this study will include small business owners in the United States. According to the United States Small Business Administration Office of Advocacy, in 2018 there were 30.2 million small businesses in the United States (Small Business Administration Office of Advocacy, 2018). The research question is focused on the personality traits of business owners in terms of obtaining microloans. Moreover, the variables of interest include personality traits, specifically, the participants' levels of extraversion, agreeableness, openness, conscientiousness, and neuroticism, as well as ability to secure microloans for business owners' respective businesses. Therefore, the best individuals to obtain data from will be small business owners in the United States.

\section{SAMPLING AND SAMPLING PROCEDURES}

The sampling frame of this study will be small business owners in the United States contacted through SurveyMonkey. To be included in the study, individuals must own a registered small business and live in the United States. For the purposes of this study, a small business will be defined as having a maximum of 1500 employees or a maximum of $\$ 38.5$ million in average annual receipts (Berisha \& Pula, 2015). This study will exclude individuals transitioning to new ownership within the next 6 months. The researcher will determine the eligibility of the participants by asking a set of screening questions based on the inclusion and exclusion criteria during the recruitment phase.

In determining the sample size for quantitative research, power analysis is a technique that is commonly used. In several quantitative studies that focus on personality traits, power analysis has been used (Donnelly \& Twenge, 2017; Pallesen, Nielsen, Magerøy, Andreassen, \& Einarsen, 2017). A power analysis was conducted using $G^{*}$ Power for two-tailed binary logistic regression (see Appendix A). Based on recommendations by Cohen (1988), a power of $80 \%$ was selected for this study. Moreover, a medium effect size (odds ratio $=1.72$ ) will be used for this study, based on common practices for different quantitative power analysis performed to determine sample sizes (Gignac, \& Szodorai, 2016; Lipsey, 1990; Wilkinson, Whittington, Perry, \& Eames, 2017). The level of significance was set at 5\%, the typical standard for statistical significance. The minimum required sample size based on these parameters is 177.

\section{PROCEDURES FOR RECRUITMENT}

Convenient purposive sampling will be used to recruit participants of the study. Convenient purposive sampling refers to a recruitment process where the participants are selected in a targeted and convenient manner based on a set of eligibility criteria (Nath, Padmawati, \& Murhandarwati, 2019). Participant recruitment will be conducted through SurveyMonkey, an online survey service with its own participant pool. The researcher will provide SurveyMonkey with the study eligibility criteria; SurveyMonkey will then distribute the survey to eligible individuals within their participant pool.

Those who are eligible will receive a copy of the informed consent form on the first page of the survey. The informed consent will include information about the purpose of the study, nature of participation, length of participation, confidentiality, and the risks involved. The informed consent form will assure the participants that involvement is strictly voluntary, explain study expectations, and emphasize the participant may choose to refrain from answering a question or withdraw from the study at any time without penalty or repercussion. The goal of the informed consent process is to ensure that potential respondents are aware of their rights and roles as participants of the study. Those who agree with the contents of the informed consent will be asked to endorse an item at the bottom of the consent page to indicate their willingness to participate. 


\section{DATA COLLECTION THROUGH ONLINE SURVEY}

After recruitment and informed consent procedures, participants will complete the online survey. All participants who agree to the informed consent page of the survey will be directed to the survey questions. Specifically, participants will answer 44 questions from the Big Five Inventory. Participants also will answer a question asking if they had secured a microloan for their business, as well as three demographic questions (age, gender, and ethnicity).

The researcher will allot seven days for the participants to answer the survey to minimize waiting time on the part of the researcher. Reminders may be sent to the participants prior to closing the survey. The researcher will close the survey after seven days or until the target number of participants has been reached.

\section{RESEARCH FINDINGS}

It is not known if and to how the personality traits of small business owners are related to their ability to secure microloans for their business needs. The purpose of this quantitative, non-experimental, correlational study is to examine how the personality traits of small business owners relate to their ability to secure microloans for their business needs.

\section{ASSUMPTION TESTING}

This assumption was met, as the dependent variable in this analysis is whether or not participants had secured a microloan for their business (yes or no). The second assumption of binary logistic regression is that there are one or more independent variables. This assumption was met, as there are five independent variables (neuroticism, extraversion, openness, conscientiousness, and agreeableness) as well as three covariate variables (age, gender, and ethnicity). The third assumption of binary logistic regression is that the observations are independent. This assumption was met, as each observation in the data was collected from a unique participant (i.e., no participants completed the survey more than one time). The fourth assumption of binary logistic regression is that there is a linear relationship between the continuous independent variables and the logit of the dependent variable.

\section{HYPOTHESIS TESTING}

To address the research questions and hypotheses, a binary logistic regression was conducted. In this analysis, the independent variables were the five personality traits measured by the Big Five Inventory (openness, conscientiousness), and the dependent variable was whether or not participants had secured a microloan for their business (yes or no). The covariate variables included in this analysis were age, gender, and ethnicity. All variables were entered into the regression model in a single step.

The statistics for the results of the binary logistic regression include the chi-square test for the overall model (chi-square value and $p$-value), and the regression coefficients for each independent variable in the model ( $B$ and $p$-values). The individual regression coefficients corresponding to the personality dimensions (openness, conscientiousness) will be assessed at a significance level of .05. If the $p$-value for the regression coefficient is less than .05 , the null hypothesis is rejected.

The statistics for the model summary are presented in Table 1. The Cox-Snell and Nagelkerke R-square measures provide estimates of the proportion of variance in the dependent variable explained by the independent variables. Approximately $24 \%$ of the variance in the dependent variable was explained by the model according to the Cox-Snell statistic, and approximately $32 \%$ of the variance in the dependent variable was explained by the model according to the Nagelkerke statistic. 
TABLE 1

MODEL SUMMARY

\begin{tabular}{lrrr}
\hline Step & $\begin{array}{r}-2 \text { Log } \\
\text { Likelihood }\end{array}$ & $\begin{array}{r}\text { Cox \& Snell } \\
\text { R-Square }\end{array}$ & $\begin{array}{r}\text { Nagelkerke } \\
\text { R-Square }\end{array}$ \\
\hline 1 & 203.77 & .24 & .32 \\
\hline
\end{tabular}

Source: Compiled by Authors - SPSS

Table 2 displays how participants' responses on the dependent variable (whether or not they secured a microloan) were classified by the model (predicted responses) versus participants' actual (observed) responses. The model correctly classified 101 out of the 125 participants who reported that they did not receive a microloan. The model correctly classified 38 out of the 71 participants who reported that they did receive a microloan. The overall percentage of correct classifications was $70.9 \%$.

TABLE 2

CLASSIFICATION TABLE

\begin{tabular}{lrrr}
\hline & \multicolumn{2}{c}{ Predicted } & \\
\cline { 2 - 3 } Observed & Did not receive loan & Received loan & Percentage Correct \\
\hline Did not receive loan & 101 & 24 & 80.8 \\
Received loan & 33 & 38 & 53.5 \\
Overall percentage & & & 70.9 \\
\hline
\end{tabular}

Source: Compiled by Authors - SPSS.

Because the overall model was significant, individual regression coefficients were examined to answer each research question and hypothesis. The regression coefficients for 1, openness, conscientiousness 1 were examined to address Research Questions 1-5 respectively.

Table 3 displays the results for the individual regression coefficients.

TABLE 3

REGRESSION COEFFICIENTS FOR BINARY LOGISTIC REGRESSION PREDICTING ABILITY TO SECURE MICROLOANS

\begin{tabular}{lrrrrrr}
\hline Variable & $B$ & $S E$ & $\chi^{2}$ & $p$ & OR & $95 \%$ CI \\
\hline Openness & 0.23 & 0.34 & 0.45 & .500 & 1.26 & {$[0.64,2.46]$} \\
Conscientiousness & -0.61 & 0.40 & 2.31 & .129 & 0.54 & {$[0.25,1.19]$} \\
Age: 36-55 years & 0.02 & 0.41 & 0.00 & .968 & 1.02 & {$[0.46,2.26]$} \\
Age: 56 or more years & -1.50 & 0.57 & 6.98 & .008 & 0.22 & {$[0.07,0.68]$} \\
Gender: Male & 1.23 & 0.36 & 11.53 & $<.001$ & 3.43 & {$[1.68,6.99]$} \\
Ethnicity: Non-White & 0.60 & 0.43 & 1.94 & .164 & 1.83 & {$[0.78,4.27]$} \\
\hline
\end{tabular}

Source: Compiled by Authors - SPSS

\section{Research Question 1}

The regression coefficient for openness was not significant $(B=0.23, p=.500)$. This indicates that openness was not significantly correlated with the ability to secure microloans after controlling for age, gender, and ethnicity. The null hypothesis $\left(\mathrm{H}_{0} 3\right)$ was not rejected. A post hoc power analysis conducted in $\mathrm{G}^{*}$ Power showed that the achieved power of this analysis with a sample of 196 participants was .84 . 


\section{Research Question 2}

The regression coefficient for conscientiousness was not significant $(B=-0.61, p=.129)$. This indicates that conscientiousness was not significantly correlated with the ability to secure microloans after controlling for age, gender, and ethnicity. The null hypothesis $\left(\mathrm{H}_{0} 4\right)$ was not rejected. A post hoc power analysis conducted in $\mathrm{G}^{*}$ Power showed that the achieved power of this analysis with a sample of 196 participants was 84 .

For Research Question 3, the results indicated that openness was not significantly correlated with the ability to secure microloans after controlling for age, gender, and ethnicity. The null hypothesis $\left(\mathrm{H}_{0} 3\right)$ was not rejected. For Research Question 4, the results indicated that conscientiousness was not significantly correlated with the ability to secure microloans after controlling for age, gender, and ethnicity. The null hypothesis $\left(\mathrm{H}_{0} 4\right)$ was not rejected.

The Big Five Inventory was used to collect data for the continuous variables of neuroticism, extraversion, openness, conscientiousness, and agreeableness. Means, standard deviations, minimum and maximum values, skewness, and kurtosis were computed for these variables. Table 4 displays descriptive statistics for the scores on each dimension of the Big Five Inventory. Participants in this sample scored highest on conscientiousness $(M=3.96, S D=0.72)$ and lowest on neuroticism $(M=2.71, S D=0.86)$.

\section{TABLE 4}

\section{DESCRIPTIVE STATISTICS FOR PERSONALITY DIMENSIONS}

\begin{tabular}{l|rrrrrr} 
VARIABLE & $\boldsymbol{M}$ & $\boldsymbol{S} \boldsymbol{D}$ & MIN & MAX & SKEWNESS & KURTOSIS \\
\hline OPENNESS & 3.84 & 0.61 & 2.20 & 5.00 & -0.36 & -0.25 \\
CONSCIENTIOUSNESS & 3.96 & 0.72 & 2.33 & 5.00 & -0.12 & -1.27 \\
\hline
\end{tabular}

Source: Compiled by Authors - SPSS

\section{RESEARCH DISCUSSION}

Microfinance loans are essential for small businesses to sustain and grow (Amatego \& Caesar, 2017; Garmaise et al., 2016). Some business owners are able to secure microloans, whereas others are unable to do so. Previous researchers examined several factors that influenced this lending, including gender (Eddleston et al., 2016; Murugesan \& Jayavelu, 2017; Pablo-Marti, Garcia-Tabuenca, \& Crespo-Espert, 2014; Robledo, Aran, Martin-Sanchez, \& Molina, 2015) and behavioral traits (Liu et al., 2015; Ren \& Zhu, 2016). Further, researchers noted the relationship between Big Five personality traits, specifically conscientiousness and openness to experience and entrepreneurial intent and success (Antonicic et al., 2013; Ayode Ezekiel et al., 2018; Farrington, 2012; Hachana et al., 2018; Ranwala \& Dissanayake, 2016). It was, however, not known whether and how personality traits of small business owners affect their ability to obtain financial aid.

The aim of this quantitative, non-experimental, correlational study was to examine the Big Five personality traits of neuroticism, extraversion, openness, conscientiousness, and agreeableness as independent variables to determine their relation with small business owners' ability to secure microloans. Collectively, the five personality traits of the participants significantly predicted small business owners' abilities to secure microloans. However, after controlling for age, gender, and ethnicity, the obtained results revealed that neuroticism, extraversion, openness, and conscientiousness were not significantly correlated with the owners' ability to secure microloans, whereas agreeableness was significantly negatively correlated with their ability to secure microloans. This chapter includes an interpretation of the findings of the present study, discussion of the limitations of the study, and recommendations and implications for the field of study based on the findings.

The findings of this study determined a negative relationship between personality attributes related to agreeableness with the ability of small business owners to secure microloans, implying that the more agreeable an individual is, the less likely they are to successfully secure financing for their microenterprise. The personality traits of openness, and conscientiousness were not significantly related with 
microenterprise owners' ability to secure financial aid. As per the overall regression model, the Big Five personality traits (independent variables) and age, gender, and ethnicity (control variables) collectively were found to significantly predict the ability of the participants to secure microloans.

The results of this quantitative study partially align with the findings of previous works related to small business enterprises. The Big Five personality traits of neuroticism, extraversion, openness, conscientiousness, and agreeableness examined in this study as independent variables have been widely investigated in neuroscience research (Allen \& DeYoung, 2017). Several scholars have studied their relations with various entrepreneurial aspects, such as entrepreneurial success (Baluku et al., 2016; Hachana et al., 2018), entrepreneurial commitment (Ayoade et al., 2018), and entrepreneurial intentions (Bazkiaei, 2020; Ettis \& Kefi, 2016; Murugesan \& Jayavelu, 2017; Ranwala \& Dissanayake, 2016; Zhao et al., 2010). Varying themes have emerged in the literature regarding the significance of these personality traits in different contexts. The present study adds to this topic by presenting an analysis which shows only one (agreeableness) of the five traits to be significant in predicting microenterprise owners' ability to secure loans.

Collectively, the findings of this study indicate that the Big Five personality traits of openness, conscientiousness predicted the success of small businesses. Overall, the personality attributes that fall under the Big Five model were found to be significant predictors of the ability of US microenterprise owners to secure loans, because entrepreneurial success is often linked with the ability to secure funding, the findings of the present study extend the work of researchers who previously linked Big Five personality traits to entrepreneurial success. For example, the present findings extend those of Baluku et al. (2016), who determined that start-up capital, extraversion, and agreeableness positively predicted entrepreneurial success, whereas neuroticism negatively predicted entrepreneurial success. These results are also similar to those of Ayoade et al. (2018), who observed a positive correlation between these personality traits and entrepreneurs' commitment.

However, the specific findings related to the regressions for individual personality factors were inconsistent in identifying agreeableness as the only statistically significant predictor of microloan receipt. Previous studies linked financial success to other Big Five traits, such as conscientiousness and openness to experience, more frequently (Antonicic et al., 2013; Ayode Ezekiel et al., 2018; Farrington, 2012; Hachana et al., 2018; Ranwala \& Dissanayake, 2016). Similarly, in a study with small businesses in the Eastern Cape Province, Farrington (2012) determined all the Big Five personality traits, except neuroticism and agreeableness, showed significant positive correlations with financial performance; neuroticism exhibited a negative relation with growth performance, and agreeableness had no relationship (Farrington, 2012). Zhao et al. (2010) found that all Big Five personality attributes, except agreeableness, were associated with entrepreneurial performance. Nevertheless, similar to this study, Leutner et al. (2014) investigated the influence of the Big Five traits on entrepreneurial outcomes, and observed that only extraversion and agreeableness showed significant effects. Although it was assumed that the relationship between business success and loan funding might illuminate the connections between Big Five personality traits and small business owners receiving funding, the mixed nature of the overall findings indicate that these connections are not immediately relatable. Below, the findings of each regression are further compared with extant literature,

\section{Openness}

The Big Five personality trait of openness was the focus of the third research question of this study, and the corresponding results show that it was not significantly related with small business owners' ability to secure loans for their microenterprises. Again, this finding was in contrast to those of previous research works, which dominantly observed a positive correlation between openness and entrepreneurship. Hachana et al. (2018), Antoncic (2009), and Antoncic et al. (2015) observed that openness to experience was positively related to entrepreneurial success, technological developments, and entrepreneurship, respectively. On the other hand, Ayoade et al. (2018) found that openness had an inverse relation with entrepreneurial commitment. The present findings indicate that lenders may not consider openness to experience as a factor in assessing the future success of prospective small business owners. 


\section{Conscientiousness}

The personality trait of conscientiousness's relationship to small business owners' abilities to secure microloans was the focus of the fourth research question of this study. Conscientiousness was not found to be significantly related to the ability of small business owners to secure financing for their trade; this result differed from the majority of studies that have examined conscientiousness in the context of business. Conscientiousness has been extensively studied in entrepreneurship research, possibly more so than the other four factors of the Big Five model, and it has mostly been determined to be essential for entrepreneurial performance (Baluku et al., 2016). Hachana et al. (2018) found that conscientiousness had a significant effect on entrepreneurial success. Ayoade et al. (2018) observed a positive correlation between conscientiousness and entrepreneurial commitment. The strong support for the relationship between conscientiousness and business success, and its lack of relationship to small business owners' abilities to secure funding, may suggest a potential factor for lenders to consider that might improve their decisionmaking capabilities.

Several reasons may exist for the inconsistency between the findings of the present study and previous research. For example, although several scholars have focused on small- and medium-sized businesses, their significance, and associated financial situations (Berisha \& Pula, 2015; Krishnan et al., 2015; Mares \& Dlasková, 2016; McGuinness \& Hogan, 2016; Rostamkalaei \& Freel, 2017), research on the owners' ability to secure loans for these businesses and the corresponding attributes of their personality has not been thoroughly conducted. Further, the variables of age, gender, and ethnicity that were considered as controls in the present study have not been systematically investigated in this context. Although the effect of gender on entrepreneurial inclination, intent, and success has been studied by some scholars (Hachana et al., 2018; Ranwala \& Dissanayake, 2016; Murugesan \& Jayavelu, 2017; Zhang et al., 2009), the moderating effect of gender on the relationship between personality traits and microenterprise owners' ability to secure loans has not been focused on in previous works. Age and ethnicity as factors in this context have been even more overlooked. Therefore, introducing these variables may have highlighted some gaps in control variables in previous studies. In that regard, the present study makes an appropriate contribution.

The educational background of the participants, as well as their physical and emotional state at the time of attempting to secure business loans, may have affected their apparent personalities and by extension, the decision about their loan. However, as this is the first study investigating this particular relationship, the theoretical framework and study design as well as the final sample population may have significantly contributed to the specific results obtained. Narrow personality traits and intelligence and emotional quotients of microenterprise owners may be more predictive of their ability to secure loans than the broad personality categories as given by the Big Five model.

\section{Recommendations}

Further researchers should also focus on a machine learning or a distributed graph algorithm approach to determine the relationship of the independent variables and covariates with the dependent variables examined in this study. With a sufficiently inclusive and diverse study sample, a qualitative study on small business owners' personality traits and their ability to secure microloans would provide a different perspective on the research topic. Self-reported analyses of the extent of neuroticism, extraversion, openness, conscientiousness, and agreeableness that participants possess would be beneficial to understand the individual's perception of why they were or were not able to obtain financing for their microenterprises. In addition, the rich, detailed data regarding lenders' choices might help to clarify the negative association between agreeableness and small business owners' abilities to secure funding.

\section{Implications}

Prior to this study, the relationship between these traits and small business owners' ability to secure microloans with age, gender, and ethnicity as control variables, however, had not been investigated. The results of this study provide valuable insights on this contemporary relationship and extend the existing literature on small businesses, personality traits, and their correlation. These findings indicate that individually, the majority of the Big Five personality traits do not significantly correlate with the ability of 
small business owners to secure microloans after controlling for age, gender, and ethnicity. In the present study, the independent variables and the control variables collectively significantly predicted the ability of small business owners to secure microloans. This has several implications in both practical and theoretical contexts.

In this study, the other four personality traits of the Big Five model (openness, and conscientiousness) were not significantly related with small business owners' ability to secure microloans. Although further research is required to form a general opinion, the results obtained in this work suggest that business owners need not focus on these aspects of their behavior when attempting to secure loans. Extraversion and openness to experience are usually considered as positive traits in social situations and contribute to the success of entrepreneurial ventures (Farrington, 2012). However, with relation to business owners' ability to secure microloans, these behavioral aspects were not found to be sufficiently significant. Similarly, personality traits related to conscientiousness, such as dependability, carefulness, thoroughness, organization, and responsibility, were not found to be significant in the context of securing business financing. Further, traits associated with neuroticism (anxiety, hostility, emotional instability), which dominantly negatively affect entrepreneurial relations, were not found to be important in the present context of the ability to secure financing.

\section{CONCLUSIONS}

The aim of the present study was to examine the relationship between the personality traits under the Big Five theoretical framework (openness, conscientiousness) and the ability of small business owners to secure microloans for their enterprises. A quantitative approach was adopted in this study and a correlational and non-experimental study design was implemented. The existing literature has substantially focused on the Big Five personality traits and the significance of small-scale business. The correlation between these personality traits and entrepreneurial aspects of business owners has been the focus of several studies; some scholars have observed positive or negative correlations between individual traits and business aspects, whereas others have not found significant correlations. The findings of this study imply an overall significant effect of personality traits on small business owners' ability to secure microloans after controlling for age, gender, and ethnicity. Individually, out of the Big Five personality traits, only agreeableness was found to be significantly negatively correlated with the ability of the participants to obtain business financing. The results add to the existing research on similar associations, and the study proposes several directions for future works.

\section{REFERENCES}

Ali, I. (2019). Personality traits, individual innovativeness and satisfaction with life. Journal of Innovation \& Knowledge, 4(1), 38-46. https://doi.org/10.1016/j.jik.2017.11.002

Allen, T.A., \& DeYoung, C.G. (2017). Personality neuroscience and the Big Five model. Oxford Handbook of the Big Five Model, pp. 319-352. https://10.1093/oxfordhb/9780199352487.013.26

Allport, G.W. (1937). Personality: A psychological interpretation. Oxford, England: Holt.

Allport, G.W. (1961). Pattern and growth in personality (14th ed.). New York: Holt, Rinehart and Winston.

Allport, G.W., \& Odbert, H.S. (1936). Trait-names: A psycho-lexical study. Psychological Monographs, 47(1), i-171. https://doi.org/10.1037/h0093360

Antonicic, B. (2015). The entrepreneur's general personality traits and technological developments. Economic and Management Engineering, 3(5), 1-6. https://doi:10.1071/s16798346413464

Antonicic, B., Bratkovic Kregar, T., Singh, G., \& DeNoble, A.F. (2013). The Big Five personalityentrepreneurship relationship: Evidence from Slovenia. Journal of Small Business Management, 53(3), 219-237. https://doi:10.1111/jsbm.12089 
Anwar, B., Xiao, Z., Fiaz, M., Ikram, A., \& Younas, M. (2017). Are leaders' personality traits imperative for employees' job performance? The Context of an Emerging Economy. Journal of Applied Business Research, 33(5), 1013. https://doi.org/10.19030/jabr.v33i5.10023

Ayoade Ezekiel, O., Ogunnaike, O.O., \& Omotayo, A. (2018). An Empirical Investigation of Direct and Indirect Effect of Personality Traits on Entrepreneurs' commitment of SMES. Journal of Entrepreneurship Education, 21. Retrieved from https://www.abacademies.org/articles/anempirical-investigation-of-direct-and-indirect-effect-of-personality-traits-on-entrepreneurs39commitment-of-smes-7235.html

Azucar, D., Marengo, D., \& Settanni, M. (2018). Predicting the Big 5 personality traits from digital footprints on social media: A meta-analysis. Personality and Individual Differences, 124, 150159. https://Doi:10.1016/j.paid.2017.12.018

Baluku, M.M., Kikooma, J.F., \& Kibanja, G.M. (2016). Does personality of owners of micro enterprises matter for the relationship between startup capital and entrepreneurial success? African Journal of Business Management, 10(1), 13-23. https://doi:10.5897/AJBM2015.7738

Banerjee, A., Duflo, E., Glennerster, R., \& Kinnan, C. (2015). The miracle of microfinance? Evidence from a randomized evaluation. American Economic Journal: Applied Economics, 7(1), 22-53. https://doi.org/10.1257/app.20130533

Barrick, M.R., \& Mount, M.K. (1991). The Big Five personality dimensions and job performance: A meta-analysis. Personnel Psychology, 44(1), 1-26. https://doi.org/10.1111/j.17446570.1991.tb00688.x

Beck, T., Degryse, H., De Haas, R., \& Van Horen, N. (2017). When arm's length is too far. Relationship banking over the business cycle. Journal of Financial Economics, 127, 174-196. https://doi.org/10.1016/j.jfineco.2017.11.007

Berger, A.N., Bouwman, C.H., \& Kim, D. (2017). Small bank comparative advantages in alleviating financial constraints and providing liquidity insurance over time. Review of Financial Studies, 30, 3416-3454. https://doi.org/10.1093/rfs/hhx038

Berisha, G., \& Pula, J.S. (2015). Defining Small and Medium Enterprises: A critical review. Academic Journal of Business, Administration, Law and Social Sciences, 1(1), 17-28. Retrieved from https://iipccl.org/wp-content/uploads/2015/03/Ajbals-17-28.pdf

Chan, K.Y., Uy, M.A., Chernyshenko, O.S., Ho, M.H.R., \& Sam, Y.L. (2015). Personality and entrepreneurial, professional and leadership motivations. Personality and Individual Differences, 77, 161-166. https://doi.org/10.1016/j.paid.2014.12.063

Cohen, J. (1988). Statistical power analyses for the social sciences. Hillsdale, NJ: Lawrence Erlbauni Associates.

Cole, R., \& Sokolyk, T. (2016). Who needs credit and who gets credit? Evidence from the surveys of small business finances. Journal of Financial Stability, 24, 40-60. https://doi:10.1016/j.jfs.2016.04.002

De Bortoli, D., da Costa, N., Jr., Goulart, M., \& Campara, J. (2019). Personality traits and investor profile analysis: A behavioral finance study. PLOS ONE, 14(3), e0214062. https://doi:10.1371/journal.pone.0214062

Delanoy, N., \& Kasztelnik, K. (2020). Business Open Data Analytics to Support Innovation Leadership and Management Decision in Canada. Business Ethics and Leadership, 4(2), 56-74. https://doi.org/10.21272/bel.4(2).56-74.2020

DeYoung, R. (2015). How relationships can reduce risk in small business lending. European Economy, 2, 87-99. Retrieved from http://european-economy.eu/

Dlugosch, T.J., Klinger, B., Frese, M., \& Klehe, U.C. (2018). Personality-based selection of entrepreneurial borrowers to reduce credit risk: Two studies on prediction models in low-and high-stakes settings in developing countries. Journal of Organizationl Behaviour. https://DOI:10.1002/job.2236 
Donnelly, K., \& Twenge, J.M. (2017). Masculine and feminine traits on the Bem Sex-Role Inventory, 1993-2012: A cross-temporal meta-analysis. Sex Roles, 76(9-10), 556-565.

https://doi.org/10.1007/s11199-016-0625-y

Eddleston, K.A., Ladge, J.J., \& Mitteness, C. (2016). Signaling effects of gender and firm characteristics on financing entrepreneurial ventures. Entrepreneurship Theory and Practice, 40(3), 489-514. https://doi.org/10.1111/etap.12117

Farrington, M. (2012). Does personality matter for small business success? South African Journal of Economic and Management Sciences, 15(4), 381-401. https://doi:10.4102/sajems.v15i4.243

Field, A. (2013). Discovering statistics using IBM SPSS statistics. Thousand Oaks, CA: Sage.

Fracassi, C., Garmaise, M.J., Kogan, S., \& Natividad, G. (2016). Business microloans for US subprime borrowers. Journal of Financial and Quantitative Analysis, 51(1), 55-83. https://doi:10.1017/S0022109016000144

Gignac, G.E., \& Szodorai, E.T. (2016). Effect size guidelines for individual differences researchers. Personality and Individual Differences, 102, 74-78. https://doi.org/10.1016/j.paid.2016.06.069

Hachana, R., Berraies, S., \& Ftiti, Z. (2018). Identifying personality traits associated with entrepreneurial success: Does gender matter? Journal of Innovation Economics Management, (3), 169-193. https://DOI:10.3917/jie.027.0169

Hassan, S., Akhtar, N., \& Y1lmaz, A.K. (2016). Impact of the Conscientiousness as Personality Trait on both Job and Organizational Performance. Journal of Managerial Sciences, 10(1). Retrieved from https://files.eric.ed.gov/fulltext/EJ1267066.pdf

John, O.P., \& Srivastava, S. (1999). The Big Five Trait taxonomy: History, measurement, and theoretical perspectives. In L.A. Pervin \& O.P. John (Eds.), Handbook of personality: Theory and research (pp. 102-138). New York, NY, US: Guilford Press. Retrieved from https://psycnet.apa.org/record/1999-04371-004

John, O.P., Donahue, E.M., \& Kentle, R.L. (1991). The Big Five Inventory--Versions $4 a$ and 54. Berkeley, CA: University of California, Berkeley, Institute of Personality and Social Research. Retrieved from https://www.ocf.berkeley.edu/ johnlab/research.htm

John, O.P., Naumann, L.P., \& Soto, C.J. (2008). Paradigm shift to the integrative big five trait taxonomy. Handbook of Personality: Theory and Research, 3(2), 114-158. Retrieved from https://www.colby.edu/psych/wp-content/uploads/sites/50/2019/06/John_et_al_2008.pdf

Johnson, R.B., \& Christensen, L. (2019). Educational research: Quantitative, qualitative, and mixed approaches. Thousand Oaks, CA: Sage.

Kariv, D., \& Coleman, S. (2015) Toward a theory of financial bricolage: The impact of small loans on new businesses. Journal of Small Business and Enterprise Development, 22(2), 196-224. https://doi:10.1108/JSBED-02-2013-0020

Kasztelnik, K. (2020). Innovative Empirical Model for Predicting National Bank's Financial Failure with Artificial Intelligence Subset Data Analysis in the United States. Open Economics, 3, 98-111. https://doi.org/10.1515/openec-2020-0106

Kerr, S.P., Kerr, W.R., \& Xu, T. (2018). Personality traits of entrepreneurs: A review of recent literature. Foundations and Trends® in Entrepreneurship, 14(3), 279-356. Retrieved from https://www.hbs.edu/faculty/Publication\%20Files/18-047_b0074a64-5428-479b-8c8316f2a0e97eb6.pdf

Leutner, F., Ahmetoglu, G., Akhtar, R., \& Chamorro-Premuzic, T. (2014). The relationship between the entrepreneurial personality and the Big Five personality traits. Personality and Individual Differences, 63, 58-63. https://doi.org/10.1016/j.paid.2014.01.042

Lipsey, M.W. (1990). Design sensitivity: Statistical power for experimental research. Sage.

Liu, Y.C., McLeod, P.L., \& Moore, O.A. (2015). Personality and small groups: An interdisciplinary perspective. Small Group Research, 46(5), 536-575. https://DOI: 10.1177/1046496415599662

McGuinness, G., \& Hogan , T. (2016). Bank credit and trade credit: Evidence from SMEs over the financial crisis. International Small Business Journal, 34(4), 412-445.

https://DOI:10.1177/0266242614558314 
Murugesan, R., \& Jayavelu, R. (2017). The influence of Big Five personality traits and self-efficacy on entrepreneurial intention: The role of gender. Journal of Entrepreneurship and Innovation in Emerging Economies, 3(1), 41-61. https://doi:10.1177/2393957516684569

Nath, T.C., Padmawati, R.S., \& Murhandarwati, E.H. (2019). Barriers and gaps in utilization and coverage of mass drug administration program against soil-transmitted helminth infection in Bangladesh: Implementation research. Journal of Infection and Public Health, 12(2), 205-212. https://doi:10.1016/j.jiph.2018.10.002

Obebo, F.M., Wawire, N.H.W., \& Muniu, J.M. (2018). Effects of participation of micro and small enterprises in microfinance on their performance in Kenya. International Journal of Economics and Finance, 10(7), 78-88. https://doi:10.5539/ijef.v10n7p78

Obschonka, M., \& Stuetzer, M. (2017). Integrating psychological approaches to entrepreneurship: The entrepreneurial personality system (EPS). Small Business Economy, 49, 203-231. https://doi:10.1007/s11187-016-9821-y

Oyeku, O.M., Oduyoye, O., Asikhia, O., Kabuoh, M., \& Elemo, G.N. (2014). On entrepreneurial success of small and medium enterprises (SMEs): A conceptual and theoretical framework. Journal of Economics and Sustainable Development, 5(16), 14-23. Retrieved from https://www.iiste.org/Journals/index.php/JEDS/article/view/15331

Pablo-Marti, F., Garcia-Tabuenca, A., \& Crespo-Espert, J.L. (2014), Do gender related differences exist in spanish entrepreneurial activities? International Journal of Gender and Entrepreneurship, 6(4), 200-214. Retrieved from https://www.cairn.info/revue-journal-of-innovation-economics-2018-3page-169.htm?ref=doi

Palazzeschi, L., Bucci, O., \& Di Fabio, A. (2018). Re-thinking innovation in organizations in the industry 4.0 scenario: New challenges in a primary prevention perspective. Frontiers in Psychology, 9 , Article ID 30. https://doi:/10.3389/fpsyg.2018.00030

Pallesen, S., Nielsen, M.B., Magerøy, N., Andreassen, C.S., \& Einarsen, S. (2017). An experimental study on the attribution of personality traits to bullies and targets in a workplace setting. Frontiers in Psychology, 8, 1045. https://doi.org/10.3389/fpsyg.2017.01045

Pang, Y., Cui, Q., Wang, Y., Chen, Y., Wang, X., Han, S., . . Chen, H. (2016). Extraversion and neuroticism related to the resting-state effective connectivity of amygdala. Scientific Reports, 6(35484), 1-9. https://doi:10.1038/srep35484

Ranwala, R.S., \& Dissanayake, D.M.N.S.W. (2016). Big five personality traits and entrepreneurial inclination: A study based on Sri Lankan undergraduates. Social and Basic Science Review, 4(4), 84-98. Retrieved from https://www.researchgate.net/publication/305189665_Big_Five_Personality_Traits_and_Entrepre neurial_Inclination_A_Study_Based_on_Sri_Lankan_Undergraduates

Ren, S., \& Zhu, Y. (2016). Developing family business through ongoing learning. Journal of General Management, 41(4), 51-70. https://doi:10.1177/030630701604100404

Robledo, J.L.R., Aran, M.A., Martin-Sanchez, V., \& Molina, M.A.R. (2015). The moderating role of gender on entrepreneurial intentions: ATPB perspective. Intangible Capital, 11(1), 92-117. http://dx.doi.org/10.3926/ic.557

Staniewski, M.W., Janowski, K., \& Awruk, K. (2016). Entrepreneurial personality dispositions and selected indicators of company functioning. Journal of Business Research, 69(5), 1939-1943. https://doi.org/10.1016/j.jbusres.2015.10.084

Taylor, A. (2017). Concentrated reasons small business owners are turned down for microloans. Journal of Business and Finance Research, 6(4), 78-86. https://doi:10.1077/s576576463135

Umadia, K., \& Kasztelnik, K. (2020). The Financial Innovative Business Strategies of Small to Medium Scale Enterprises in Developing Country and Influence for the Global Economy Performance. SocioEconomic Challenges, 4(3), 20-32. https://doi.org/10.21272/sec.4(3).20-32.2020

Viinikainen, J., Heineck, G., Böckerman, P., Hintsanen, M., Raitakari, O., \& Pehkonen, J. (2017). Born entrepreneurs? Adolescents' personality characteristics and entrepreneurship in adulthood. 
Journal of Business Venturing Insights, 8, 9-12. Retrieved from

https://ideas.repec.org/p/iza/izadps/dp9805.html

Wilkinson, H., Whittington, R., Perry, L., \& Eames, C. (2017). Does formulation of service users' difficulties improve empathy in forensic mental health services. Journal of Forensic Psychology Research and Practice, pp. 1-22. https://doi.org/10.1080/24732850.2017.1297758 